\title{
How well is the electronic health record supporting the clinical tasks of hospital physicians? A survey of physicians at three Norwegian hospitals
}

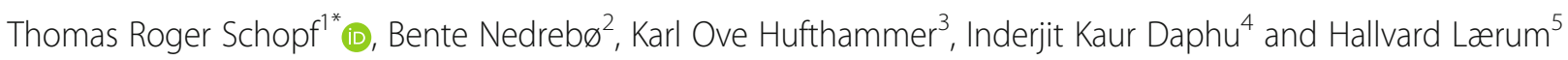

\begin{abstract}
Background: The electronic health record is expected to improve the quality and efficiency of health care. Many novel functionalities have been introduced in order to improve medical decision making and communication between health care personnel. There is however limited evidence on whether these new functionalities are useful. The aim of our study was to investigate how well the electronic health record system supports physicians in performing basic clinical tasks.

Methods: Physicians of three prominent Norwegian hospitals participated in the survey. They were asked, in an online questionnaire, how well the hospital's electronic health record system DIPS supported 49 clinical tasks as well as how satisfied they were with the system in general, including the technical performance. Two hundred and eight of 402 physicians (52\%) submitted a completely answered questionnaire.

Results: Seventy-two percent of the physicians had their work interrupted or delayed because the electronic health record hangs or crashes at least once a week, while 22\% had experienced this problem daily. Fifty-three percent of the physicians indicated that the electronic health record is cumbersome to use and adds to their workload. The majority of physicians were satisfied with managing tests, e.g., requesting laboratory tests, reading test results and managing radiological investigations and electrocardiograms. Physicians were less satisfied with managing referrals. There was high satisfaction with some of the decision support functionalities available for prescribing drugs. This includes drug interaction alerts and drug allergy warnings, which are displayed automatically. However, physicians were less satisfied with other aspects of prescribing drugs, including getting an overview of the ongoing drug therapy.

Conclusions: In the survey physicians asked for improvements of certain electronic health record functionalities like medication, clinical workflow support including planning and better overviews. In addition, there is apparently a need to focus on system stability, number of logins, reliability and better instructions on available electronic health record features. Considerable development is needed in current electronic health record systems to improve usefulness and satisfaction.
\end{abstract}

Keywords: Electronic health record, Information and communication technology, Hospital physician, Clinical task, Clinical decision support

\footnotetext{
* Correspondence: thomas.schopf@ehealthresearch.no

${ }^{1}$ Norwegian Centre for E-health Research, University Hospital of

North-Norway, P.O. Box 35, 9038 Tromsø, Norway

Full list of author information is available at the end of the article
}

(c) The Author(s). 2019 Open Access This article is distributed under the terms of the Creative Commons Attribution 4.0 International License (http://creativecommons.org/licenses/by/4.0/), which permits unrestricted use, distribution, and reproduction in any medium, provided you give appropriate credit to the original author(s) and the source, provide a link to the Creative Commons license, and indicate if changes were made. The Creative Commons Public Domain Dedication waiver (http://creativecommons.org/publicdomain/zero/1.0/) applies to the data made available in this article, unless otherwise stated. 


\section{Background}

Information and communication technology (ICT) has become an essential part of the daily work of clinicians. Electronic health record (EHR) systems are expected to make health care services more efficient, reduce the workload of the clinician and prevent medical errors [1-5]. They can document diagnostic investigations and medical treatment, provide clinical decision support and facilitate communication between health care personnel. In addition, there is a growing demand to extract large data sets from the EHR for administrative reporting, clinical audits and research [5-7]. In the Nordic countries the EHR has become a standard tool for clinicians [8]. In recent years, improved EHR versions with an increasing number of functionalities have been implemented at Norwegian hospitals. According to the EHR vendors, these new releases are comprehensive and capable of providing all the features needed to support clinical work, patient administration and to facilitate research [9].

However, there is limited evidence on whether these new functionalities are beneficial $[2,10]$. Positive effects are not guaranteed after implementing new EHR systems, and reports have indicated a variety of possible negative effects $[1,11,12]$, especially regarding the usability of EHR systems [13]. For instance, Baumann et al. found that the time clinicians spend for documentation has increased after the introduction of EHR systems [14]. These experiences may also be related to nonclinical workload, e.g., documentation of coding and quality measures [13]. While many studies in the literature have focused on the implementation processes of EHR systems, there are few reports about fully adopted systems after longer periods of use [14-16]. A study by Kaipio et al. indicated that the usability of EHR functionalities in Finnish hospitals had not improved much during a 4 year period [16]. Both physicians and researchers have raised concerns that poor usability of the EHR may ultimately reduce the quality of clinical care $[17,18]$.

Research within cognitive informatics has increasingly been focusing on the use of ICT in clinical work environments, especially emphasizing the human computer interaction in a real world clinical context [19]. The "TURF" framework defines EHR usability in terms of how useful, usable and satisfying the EHR is in the clinical context [20]. Under "TURF", usefulness refers to how well the system supports the users in accomplishing clinical tasks. A system is usable if it is easy to learn, intuitive to operate and with a low error rate. However, a system might be very usable, but still not useful if it does not support clinical tasks. A clinical task may refer to simple operations such as prescribing a drug or more complex processes such as gathering information for the discharge letter. Knowledge about usefulness is essential for improving deficiencies in the current systems, and for developing better EHR systems in the future. The aim of our study was to investigate the usefulness of EHR systems currently implemented in Norway. We were particularly interested in how well the clinical tasks were supported by EHR functionalities.

Since the technical infrastructure (e.g., computer processing power and speed) will influence the performance of the EHR, we also examined the perceived usefulness of the entire ICT environment. We sought to answer these research questions:

- How useful is the EHR?

- Which EHR functionalities are missing, and which need to be improved?

- What is the overall satisfaction with the EHR?

- How satisfied are physicians with the general ICT performance, e.g., system response time and reliability?

\section{Methods \\ Setting}

Several in- and outpatient clinics at three Norwegian hospitals participated in the study: Oslo University Hospital (OUH), Haukeland University Hospital (HUH) and Haraldsplass Deaconess Hospital (HDH). Each hospital had implemented the EHR system DIPS (DIPS ASA, Oslo) over the previous years (OUH in 2014, HUH and HDH in 2010). DIPS is one of the major EHR systems in Norway designed for clinical documentation, lab test management and prescription of drugs. All hospitals had the same version of DIPS. In addition to DIPS, there are several other independent ICT systems to help physicians in their clinical work - systems for radiological image archives, pathology reporting, etc.

\section{Data collection}

A random selection of physicians at several clinical departments at the three hospitals was invited by email to participate in an online survey. While the head of each department provided the email addresses, all invitations (and reminders in case of no answer) were managed by the researchers. The departments were selected in such a way that the number of physicians from medical and surgical specialties could be balanced. The survey was conducted between November 2015 and September 2016. In case of no response, up to 10 reminders were sent.

\section{The questionnaire}

The web-based tool LimeSurvey (LimeSurvey $\mathrm{GmbH}$, Hamburg) was used for the online questionnaire. The tool automatically sent email reminders to participants and handled all data without disclosing any personal information (including IP-addresses). The questionnaire was developed by two of the authors (BN and HL) based 
on similar validated questionnaires used in previous studies, including a validated questionnaire from Lærum \& Faxvaag (median kappa for use-related items 0.72 and for satisfaction-related items 0.62 ) [21, 22]. In a pilot trial (unpublished) in 2012, seven physicians from different clinical specialties reviewed the questionnaire, and their feedback was used to improve it. Our survey was thematically organized in the following three dimensions.

\section{Dimension 1: technical performance}

The physicians were asked about the technical performance of the EHR system, e.g., "How many times daily do you log in to access patient related information?" Further questions addressed computer response time, stability issues and the integration between different EHR applications.

\section{Dimension 2: clinical tasks}

The physicians rated the compatibility of the clinical tasks with the functionality of the EHR. We examined 49 common clinical tasks (Fig. 1) regularly performed by physicians, along with the corresponding EHR functionalities designed to support these tasks. The tasks were selected based on previous studies [21, 23]. The questionnaire used branching logic to limit the total number of questions each physician had to answer (Fig. 2). Up to four questions were presented for each clinical task. First, each task was precisely defined. In question 1 in each four-question group, we asked if the EHR at the physician's workplace had a functionality to support this clinical task. In addition to 'Yes' and 'No', the physician could also respond 'Not relevant' (e.g., if the task was never performed) and 'I don't know'. In question 2, we asked how frequently the physician used this EHR functionality in their daily work. In question 3, we asked how satisfied the physician was with the EHR functionality. If the physician responded 'Not relevant' in question 1 , the remaining questions on the functionality were omitted. Instead, the four questions for the next clinical task were presented. If the physician responded 'No' or 'I don't know' to question 1, a question on how important it would be to have this functionality was presented (question 4). If the answer to question 2 was 'Never' or 'Almost never', the physician was directed to a question asking how important it would be to improve such a functionality (question 4). The wording of question 4 would thus slightly change, depending on which answers were ticked in the previous questions.

Satisfaction was rated using 5-point Likert items (response options 'Very dissatisfied', 'Moderately dissatisfied', 'Neutral', 'Moderately satisfied', 'Very satisfied'). The importance of improvements (question 4) was rated on a 4point ordinal rating scale (response options 'Not important', 'Slightly important', 'Important', 'Very important').

\section{Dimension 3: overall satisfaction}

The physicians rated their agreement to statements regarding their overall satisfaction with the EHR system using 5-point Likert items ('Completely disagree', 'Partially disagree', 'Neutral', 'Partially agree, 'Completely agree'). Half of the statements were positively worded (i.e., 'Completely agree' indicated satisfaction with the EHR) and half of the statements were negatively worded (i.e., 'Completely agree' indicated dissatisfaction with the EHR).

\section{Analysis / statistical methods}

For questions with categorical response options, we report counts and/or percentages for each possible response. For questions on the importance of having improvements in the EHR system, we scored the 4-point rating scale using the numerical values $0-3$ and report the mean scores, along with 95\% confidence intervals. To compute the confidence intervals, we used the percentile bootstrap, with 9999 bootstrap replications. We used $\mathrm{R}$ version 3.3.0-3.5.1 [24] to analyse the data and prepare the figures (except for the flowchart).

\section{Ethics}

The Regional Committee for Medical and Health Research Ethics South East Norway has been consulted. According to national regulations ethics approval was not required because the study did not involve biomedical research and all data were anonymised.

\section{Results}

The results are presented for all hospitals together. A total of 402 physicians were enrolled from three Norwegian hospitals, and 208 physicians (52\%) submitted a completely answered questionnaire (Table 1). Physicians who reported that they had no patient contact or had been employed for less than 3 months, were excluded.

\section{Dimension 1}

Only $21 \%$ of the physicians were satisfied or very satisfied with the processing speed of the EHR. Seventy-two percent of the physicians had their work interrupted or delayed because the EHR hanged or crashed at least once a week, while $22 \%$ had experienced this problem daily. Sixty-two percent of the physicians had to log in with a username and password more than 10 times per day, and 32\% more than 20 times per day. Regarding the use of additional ICT systems, 58\% reported that they were using more than one ICT system to access the patient data, and $10 \%$ were using more than three. For physicians using more than one ICT system, $82 \%$ had to look up the patient manually when logging in to two or more ICT systems, i.e., there was no functionality to automatically recognize which patient the physician was 


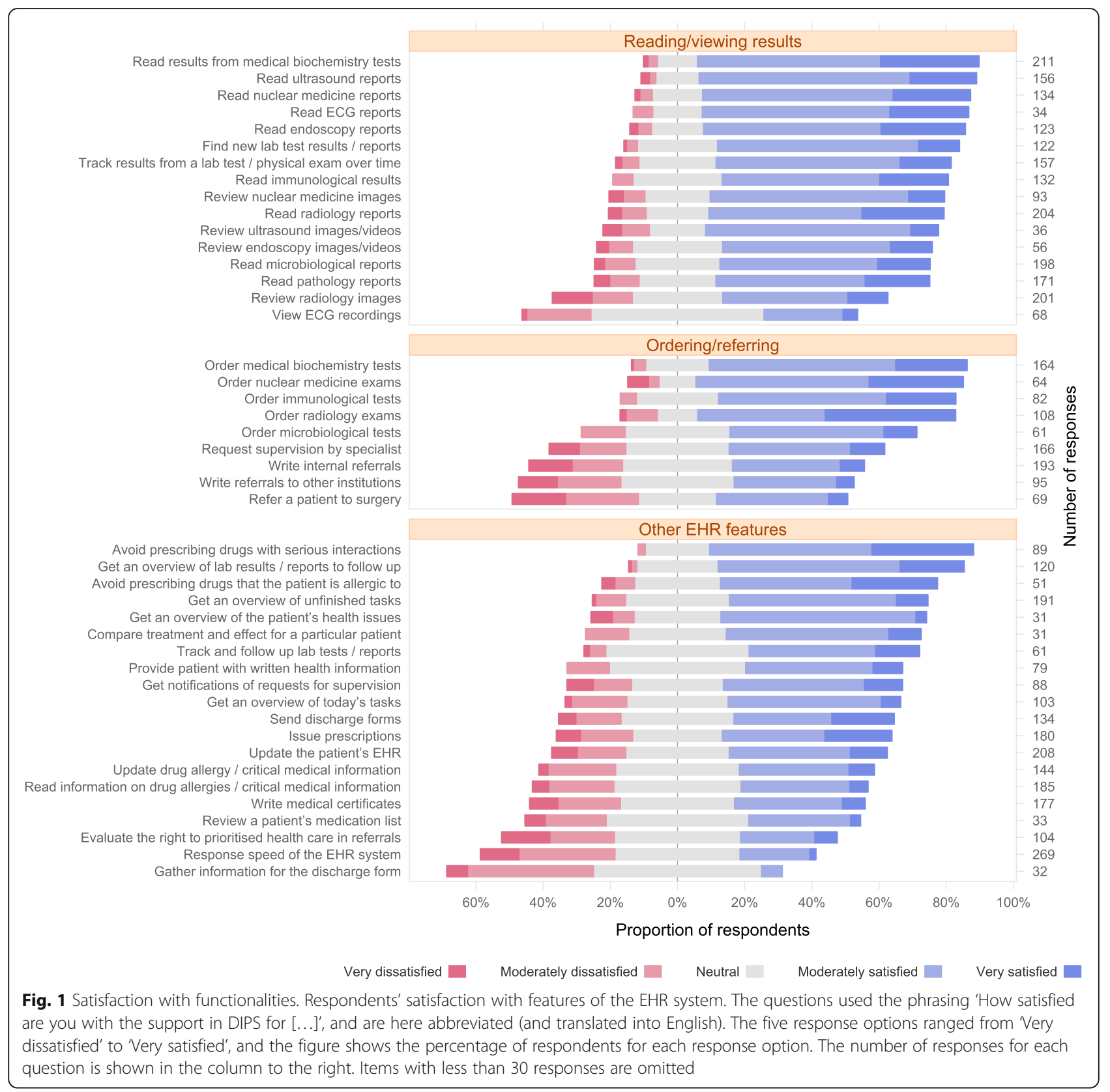

currently working on. Thirty-one percent responded that such a manual search was required with four or more ICT systems.

\section{Dimension 2}

Figures 1 and 3 show a selection of the results for dimension 2, arranged in functional categories corresponding to the clinical tasks.

\section{Dimension 3}

Figure 4 summarizes the results of dimension 3 .

\section{Discussion}

The majority of Norwegian doctors have been using EHR systems since the beginning of the twenty-first century $[5,8]$. The EHR system in this study represents a fully adopted system, in contrary to previous usability studies in which the EHR systems were typically in a post-implementation setting demonstrating initial use experiences only [14-16].

Our findings indicated poor technical performance of the EHR. It appears that physicians often have to wait due to hanging computer systems. Based on our data, it is not possible to assess if these problems are caused by the EHR system itself, the operating system or the 


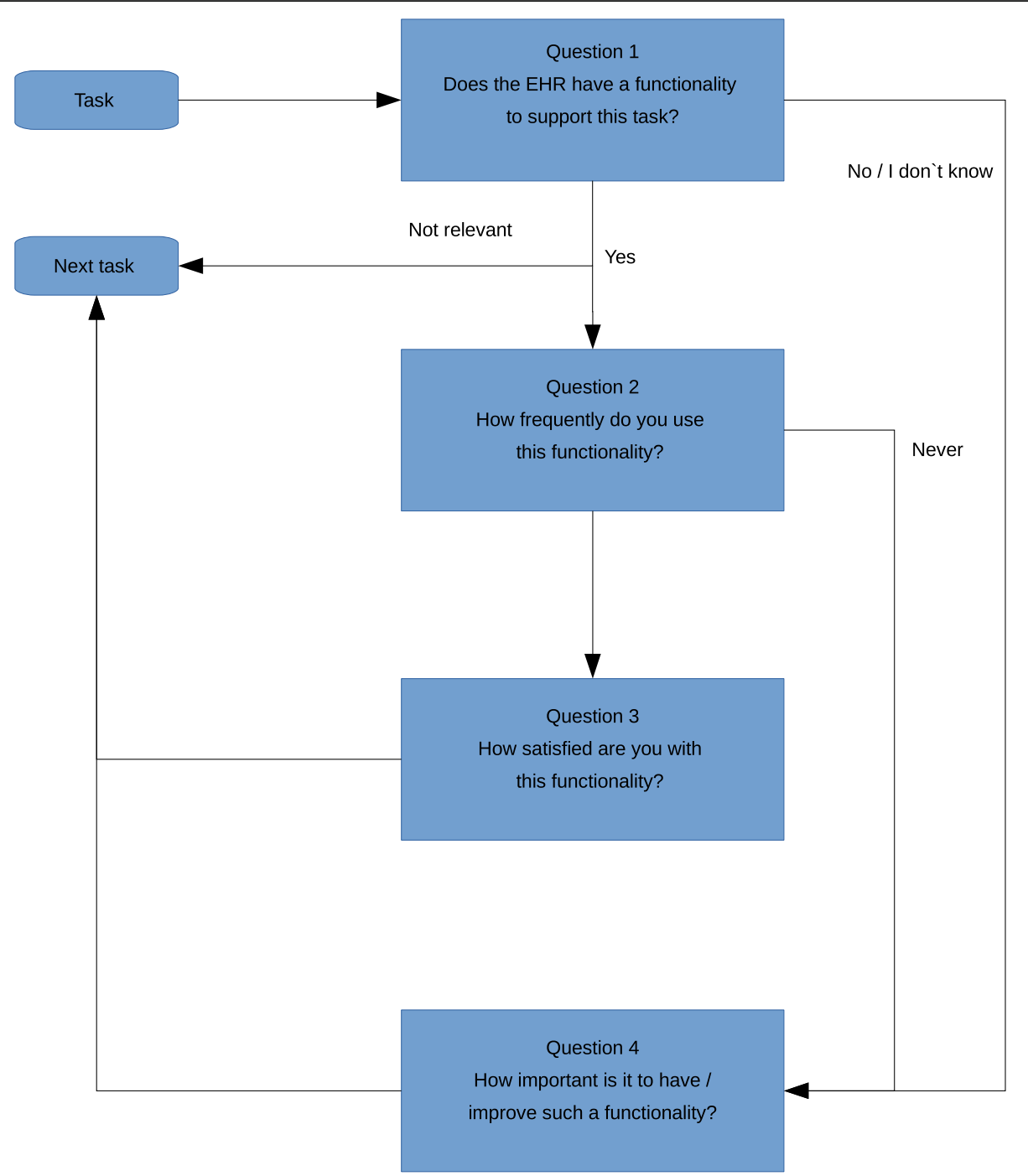

Fig. 2 Flowchart. The flowchart displays the sequence of questions used in the survey

computer hardware. Yoo et al. studied requests for EHR improvements in a major Korean hospital and found no indications of poor ICT stability or hardware problems [25]. In contrast, Hyppönen et al. reported moderate satisfaction with system stability in Nordic hospitals [26].

Another time-consuming task is having to look up patients repeatedly when logging on other ICT systems. As different software companies may be involved, there might be no easy solution to this problem in the short run. However, health authorities in Norway have called for complete and easy access to all of the patient's health data. As a potential result of standardization and integration of various data sources and computer applications, in the future, only a single EHR interface may be needed for clinicians to access all health data from both primary and secondary health care providers [5, 27].
We found several deficiencies in the compatibility of the EHR system with the most common clinical tasks. Few studies have examined the usefulness of EHR systems in terms of how well clinical tasks are supported. Kaipio and Viitanen have included clinical tasks in their studies, but in the questions presented to clinicians many similar functionalities were merged into groups $[10,16]$. Novel EHR systems have complex functionalities which may consist of several minor "subfunctions" [5, 28]. For instance, instead of asking physicians about the overall usefulness of the drug management functionality, we have tried to elaborate on this by including all relevant EHR subfunctions available for managing drugs. There was high satisfaction with some of the decision support functionalities available for prescribing drugs (Fig. 1). This includes drug interaction alerts and drug allergy warnings, which are displayed automatically. However, physicians were less 
Table 1 Respondent demographics

\begin{tabular}{llll}
\hline & OUH & $\mathrm{HUH}+\mathrm{HDH}$ & Sum \\
\hline Hospital departments & & & \\
$\quad$ Neurology & 81 & & 81 \\
Ear-Nose-Throat (ENT) & 41 & & 41 \\
Orthopaedics & 33 & & 33 \\
Oncology & 73 & $40+0$ & 113 \\
$\quad$ Internal medicine & & $40+60$ & 100 \\
$\quad$ Surgical dpt. & 228 & 201 & 429 \\
Sum invited & 4 & 23 & 27 \\
Excluded & 224 & 178 & 402 \\
Total & & & \\
Responses & $117(52 \%)$ & $91(51 \%)$ & $208(52 \%)$ \\
$\quad$ Complete responses & $161(72 \%)$ & $141(79 \%)$ & $302(75 \%)$ \\
Complete and partial responses & $47 \%$ & $40 \%$ & $44 \%$ \\
\hline Female respondents & $47 \%$ \\
\hline
\end{tabular}

satisfied with other aspects of prescribing drugs, including getting an overview of the ongoing drug therapy. These findings indicate that a thorough examination of the different subfunctions of a complex functionality is needed in order to get a better understanding of how functionalities really work.

The majority of physicians were satisfied with managing tests, e.g., requesting and reading laboratory test results, radiological investigations and ECGs (Fig. 1). However, physicians were less satisfied with viewing radiological images or ECG recordings. Instead of accessing the final summary report, typically provided by specialists in radiology and cardiology, many physicians may find it useful to see the original image or ECG recording. This may be particularly relevant in emergencies, when there is no time to wait for the specialist's interpretation, or when there is no specialist physically present at all, e.g., in small county hospitals.

Physicians were moderately satisfied with managing referrals, including incoming referrals as well as referrals of patients to other departments or hospitals. However,

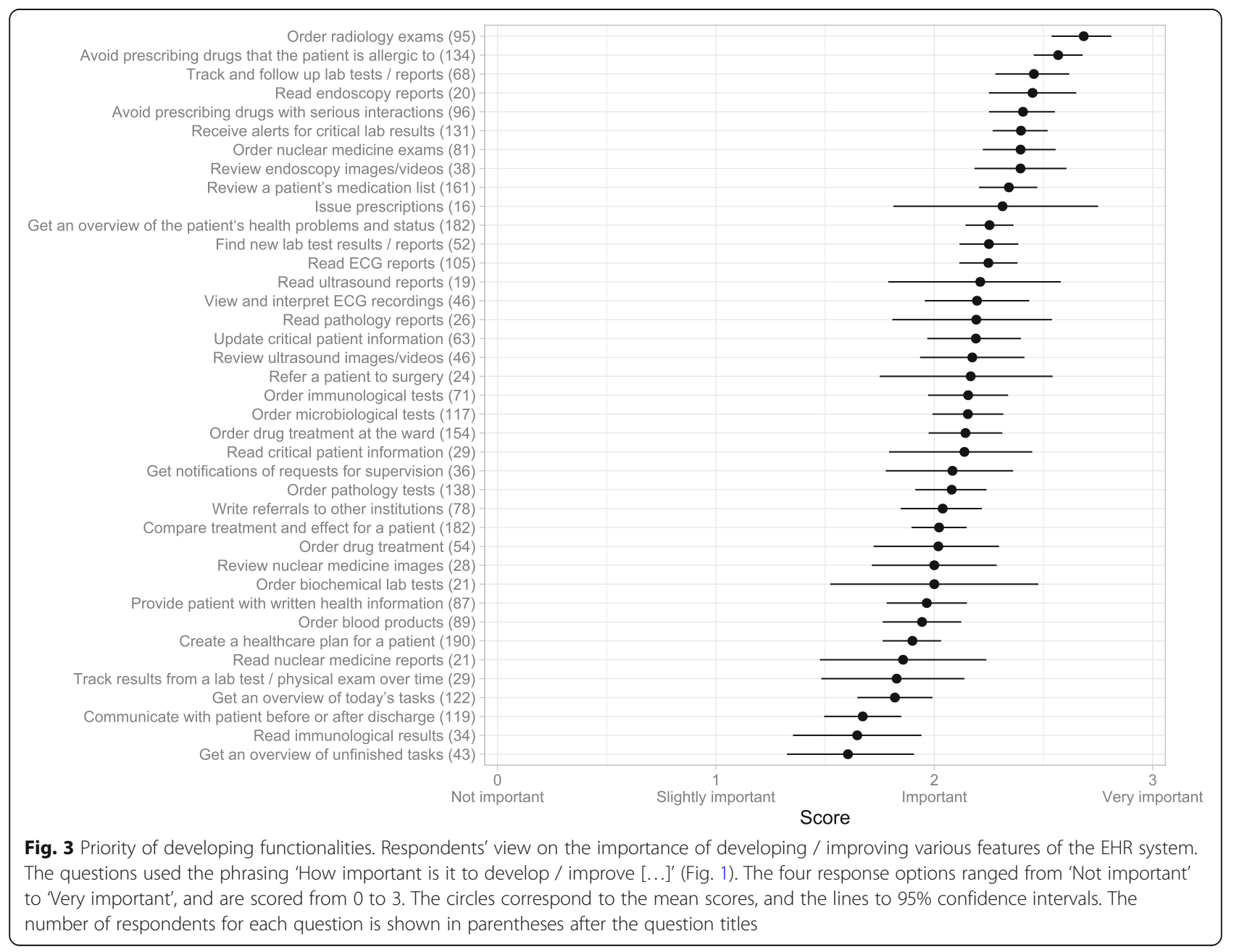




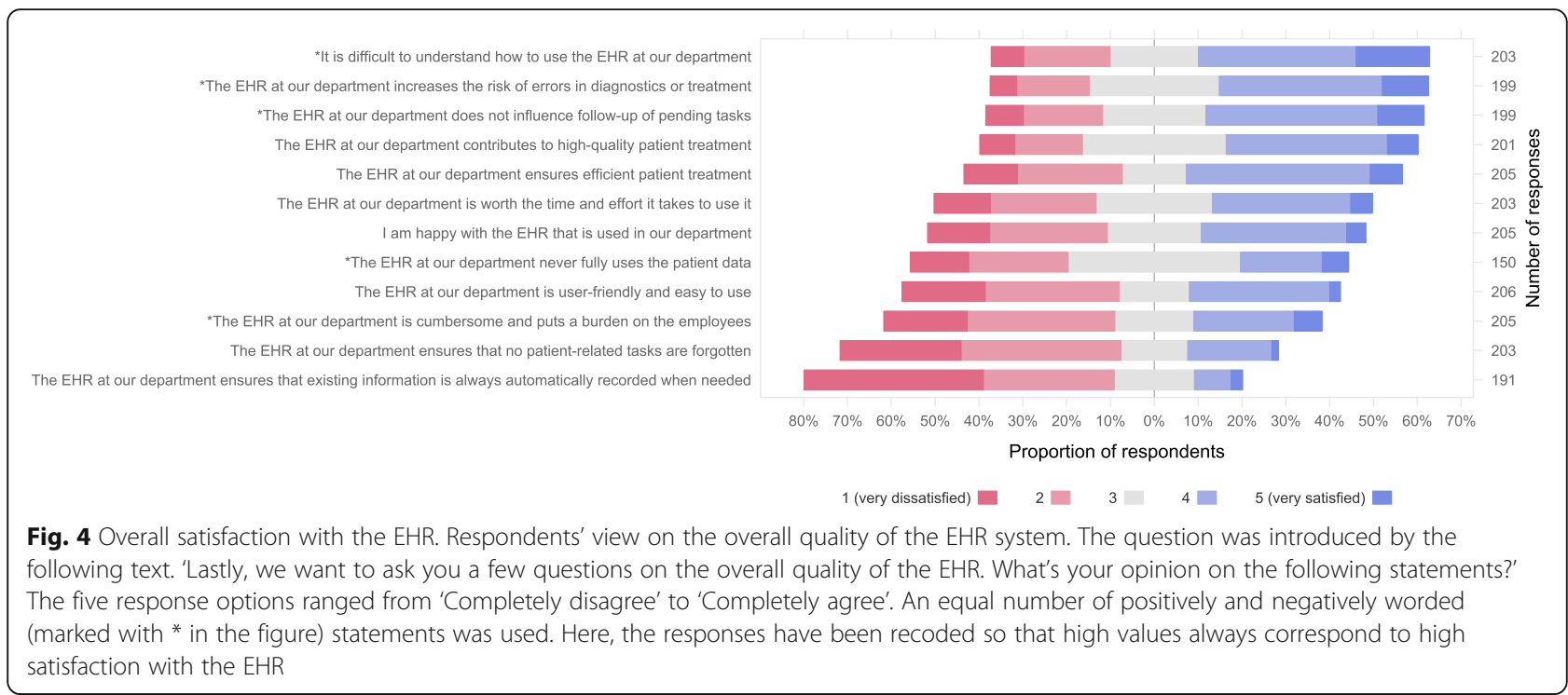

many physicians were dissatisfied with the functionality for writing and editing summary notes to primary health care, including discharge letters (Fig. 1).

We found that many items with high satisfaction scores apparently represent 'simple' functionalities, such as requesting and displaying lab results. There were only a few exceptions to this, e.g., the drug interaction and allergy warning alerts. Many basic and frequently used functionalities, such as managing sick notes or prescribing drugs, received only moderate scores (Fig. 1). Other examples include communication features for improving the interaction with other clinicians (e.g., discharge letters or referrals). In our opinion, important functionalities such as managing sick notes or prescribing drugs need urgent improvement. Since they represent specific and well-known procedures previously managed by simple paper forms, we are confident that neither complicated interface design work nor excessive computer processing power is needed to accomplish this.

Sixty-four percent of physicians correctly identified if the EHR had a functionality to support a certain clinical task (question 1). This may imply that the instructions given to physicians regarding the available features of the EHR are insufficient, as a considerable number of functionalities appears to be unknown. Similar findings have been reported by Price et al. [29].

Some of the overall scores in dimension 3 are low (Fig. 4). For instance, many physicians indicated that the EHR adds to their workload and may in fact be the cause of medical errors. There have been reports in the literature regarding concerns about safety and possible patient harm [1, 30-32]. Howe et al. reported that such adverse events might be due to a great variety of EHR usability issues, including data entry procedures and poor visual display of information [30].
Previously, the main purpose of patient health records was simply to document the work of clinicians, but the EHR is now expected to support the decision making process $[1,5,18]$. Modern decision support systems can potentially provide the clinician with all relevant previously recorded information needed to diagnose and provide medical treatment. The basic idea is to retrieve and process information automatically, and to make relevant data accessible to the clinician. The ultimate goal is to prevent medical errors, improve patient outcome and reduce the time the clinician has to spend searching for and recording information.

Sinsky has asked for a fundamental review of how the EHR is designed and integrated into the workflow of clinicians. She pointed out that even basic security tasks such as multiple log-in procedures may lead to increased workload and distract from clinical work [33]. In our opinion the findings in this study may support her views.

Limitations: The number of respondents in our study is limited. The results might be different in a larger study. In addition to DIPS, the physicians were using other independent ICT systems. We are aware that some of these systems are not the same at the 3 hospitals. Therefore some of the data might not be comparable. However, we analysed the data from each hospital separately and found no major differences. Since only physicians participated in our survey, we have no data to indicate the perceptions of other clinicians. Several professions use EHRs and their needs might differ from that of physicians. Also, we have little knowledge regarding users' expectations of the EHR. The usability issues identified in our study may be related to poor functionalities. However, we have not considered insufficient navigational design, e.g., if the clinician has to perform many mouse clicks or spend time scrolling down a huge 
document. As a consequence, the quality of that functionality may be perceived as poor. Finally, to our knowledge, the EHR systems studied are implemented in Norway only. The results may thus not be generalizable to EHR systems of other countries. Nevertheless, we believe that some common themes emerging from our study are of interest to the research community.

\section{Conclusion}

In the survey physicians asked for improvements of many EHR functionalities. In addition, there is apparently a need to focus on system stability, number of logins, reliability, better instructions on available EHR features and improved integration between different clinical ICT systems and the EHR. Considerable development is needed in current EHR systems to improve usefulness and satisfaction.

\section{Abbreviations}

EHR: Electronic health record; HDH: Haraldsplass Deaconess Hospital; HUH: Haukeland University Hospital; ICT: Information and communication technology; OUH: Oslo University Hospital

\section{Acknowledgements}

The authors would like to thank all physicians for participating in the online survey.

\section{Authors' contributions}

All authors contributed to writing this article. $\mathrm{HL}$ and $\mathrm{BN}$ were responsible for study design. $\mathrm{HL}, \mathrm{BN}$ and ID contributed to data collection. $\mathrm{KOH}$ did the statistical analyses and prepared Figs. 1, 3 and 4. TS had the main responsibility for data interpretation and drafted the manuscript. $\mathrm{BN}, \mathrm{ID}, \mathrm{KOH}$ and $\mathrm{HL}$ contributed to data interpretation and manuscript writing. All authors read and approved the final manuscript.

\section{Funding}

The authors received no specific funding for this work.

\section{Availability of data and materials}

The datasets generated and analysed during the current study are available from the corresponding author on reasonable request.

\section{Ethics approval and consent to participate}

According to national regulations ethics approval was not required because the study did not involve biomedical research and all data were anonymised. The Regional Committees for Medical and Health Research Ethics South East has been consulted and agreed with voluntary submission of the questionnaire as consent to participate in the study.

\section{Consent for publication}

Not applicable.

\section{Competing interests}

The authors declare that they have no competing interests.

\section{Author details}

${ }^{1}$ Norwegian Centre for E-health Research, University Hospital of North-Norway, P.O. Box 35, 9038 Tromsø, Norway. ${ }^{2}$ Norwegian Board of Health Supervision, P.O. Box 231 Skøyen, 0213 Oslo, Norway. ${ }^{3}$ Centre for Clinical Research, Haukeland University Hospital, P.O. Box 1400, 5021 Bergen, Norway. ${ }^{4}$ Section for e-Health, Department for Research and Development, Haukeland University Hospital, P.O. Box 1400, 5021 Bergen, Norway. ${ }^{5}$ The Norwegian Directorate for e-health, P.O. Box 221 Skøyen, 0213 Oslo, Norway.
Received: 10 June 2019 Accepted: 20 November 2019

Published online: 04 December 2019

\section{References}

1. Graber ML, Byrne C, Johnston D. The impact of electronic health records on diagnosis. Diagnosis (Berl). 2017 Nov 27:4(4):211-23.

2. Black AD, Car J, Pagliari C, Anandan C, Cresswell K, Bokun T, et al. The impact of eHealth on the quality and safety of health care: a systematic overview. PLoS Med. 2011:8:e1000387.

3. Hoerbst A, Ammenwerth E. Electronic health records. A systematic review on quality requirements. Methods Inf Med. 2010;49(4):320-36.

4. Häyrinen K, Saranto K, Nykänen P. Definition, structure, content, use and impacts of electronic health records: a review of the research literature. Int J Med Inform. 2008 May;77(5):291-304.

5. Meld.St.9. (2012-2013). En innbygger - en journal. Digitale tjenester i helseog omsorgssektoren. https://www.regjeringen.no/no/dokumenter/meld-st9-20122013/id708609/. In Norwegian.

6. Bjugn R, Casati B, Haugland HK. Structured electronic health records. Tidsskr Nor Laegeforen. 2014 Feb 25;134(4):431-3.

7. Dehli W, Lærum H, Nedrebø BS. Gi data tilbake til fagfolkene! Dagens Medisin. 2013; 15.08.2013:22. In Norwegian.

8. Nøhr C, Koch S, Vimarlund V, Gilstad H, Faxvaag A, Hardardottir GA Andreassen HK, Kangas M, Reponen J, Bertelsen P, Villumsen S, Hyppönen $H$. Monitoring and benchmarking eHealth in the Nordic countries. Stud Health Technol Inform. 2018;247:86-90.

9. Our solutions. DIPS AS. https://www.dips.com/uk/solutions. Accessed 3 January 2019.

10. Viitanen J, Hyppönen H, Lääveri T, Vänskä J, Reponen J, Winblad I. National questionnaire study on clinical ICT systems proofs: physicians suffer from poor usability. Int J Med Inform. 2011 Oct;80(10):708-25.

11. Eden R, Burton-Jones A, Scott I, Staib A, Sullivan C. Effects of eHealth on hospital practice: synthesis of the current literature. Aust Health Rev. 2018 Jul; 10.

12. Lau F, Price M, Boyd J, Partridge C, Bell H, Raworth R. Impact of electronic medical record on physician practice in office settings: a systematic review. BMC Med Inform Decis Mak. 2012 Feb 24:12:10.

13. Tutty MA, Carlasare LE, Lloyd S, Sinsky CA. The complex case of EHRs: examining the factors impacting the EHR user experience. J Am Med Inform Assoc. 2019 Jul 1;26(7):673-7.

14. Ellsworth MA, Dziadzko M, O'Horo JC, Farrell AM, Zhang J, Herasevich V. An appraisal of published usability evaluations of electronic health records via systematic review. J Am Med Inform Assoc. 2017 Jan;24(1):218-26.

15. Baumann LA, Baker J, Elshaug AG. The impact of electronic health record systems on clinical documentation times: a systematic review. Health Policy. 2018 Aug:122(8):827-36.

16. Kaipio J, Lääveri T, Hyppönen H, Vainiomäki S, Reponen J, Kushniruk A, Borycki E, Vänskä J. Usability problems do not heal by themselves: national survey on physicians' experiences with EHRs in Finland. Int J Med Inform. 2017 Jan;97:266-81.

17. Rosenbaum L. Transitional Chaos or enduring harm? The EHR and the disruption of medicine. N Engl J Med. 2015 Oct 22;373(17):1585-8.

18. Gardner RM. Clinical Information Systems - From Yesterday to Tomorrow. Yearb Med Inform. 2016 Jun 30;Suppl 1:S62-75.

19. Kannampallil TG, Patel VL. Special issue on cognitive informatics methods for interactive clinical systems. J Biomed Inform. 2017 Jul;71:207-10.

20. Zhang J, Walji MF. TURF: toward a unified framework of EHR usability. J Biomed Inform. 2011 Dec:44(6):1056-67.

21. Laerum H, Faxvaag A. Task-oriented evaluation of electronic medical records systems: development and validation of a questionnaire for physicians. BMC Med Inform Decis Mak. 2004;4:1.

22. Heimly V, Grimsmo A, Henningsen TP, Faxvaag A. Diffusion and use of electronic health record systems in Norway. Stud Health Technol Inform. 2010;160(Pt1):381-5.

23. Laerum $H$, Ellingsen $G$, Faxvaag A. Doctors' use of electronic medical records systems in hospitals: cross sectional survey. BMJ. 2001 Dec 8; 323(7325):1344-8

24. R Core Team. R: a language and environment for statistical computing. In: R Foundation for statistical computing. Vienna; 2018. https://www.R-project.org/.

25. Yoo S, Kim S, Lee S, Lee KH, Baek RM, Hwang $\mathrm{H}$. A study of user requests regarding the fully electronic health record system at Seoul National University Bundang hospital: challenges for future electronic health record systems. Int J Med Inform. 2013 May;82(5):387-97. 
26. Hyppönen H, Kangas M, Reponen J, Nøhr J, Villumsen S, Koch S, Hardardottir AG, Gilstad H, Jerlvall L, Pehrsson T, Faxvaag A, Andreassen $H$ Brattheim B, Vimarlund V, Kaipio J. Nordic eHealth Benchmarking: Status 2014. Tema Nord 2015:539. Copenhagen: Nordic Council of Ministers. https://www.norden.org/en/publication/nordic-ehealth-benchmarking.

27. Faxvaag A, Ree AO, Nedrebø BS. Journalsystem til bedre nytte. Computerworld It:helse. 2012 August; In Norwegian.

28. Dyb K, Warth LL. The Norwegian National Summary Care Record: a qualitative analysis of doctors' use of and trust in shared patient information. BMC Health Serv Res. 2018 Apr 6;18(1):252.

29. Price $M$, Singer A, Kim J. Adopting electronic medical records: are they just electronic paper records? Can Fam Physician. 2013 Jul;59(7).

30. Howe JL, Adams KT, Hettinger AZ, Ratwani RM. Electronic health record usability issues and potential contribution to patient harm. JAMA. 2018 Mar 27;319(12):1276-8.

31. Bowman S. Impact of electronic health record systems on information integrity: quality and safety implications. Perspect Health Inf Manag. 2013 Oct 1;10:1c

32. Ratwani RM, Savage E, Will A, Arnold R, Khairat S, Miller K, Fairbanks RJ Hodgkins M, Hettinger AZ. A usability and safety analysis of electronic health records: a multi-center study. J Am Med Inform Assoc. 2018 Sep 1; 25(9):1197-201.

33. Sinsky CA, Privitera MR. Creating a "manageable cockpit" for clinicians: a shared responsibility. JAMA Intern Med. 2018 Jun 1;178(6):741-2.

\section{Publisher's Note}

Springer Nature remains neutral with regard to jurisdictional claims in published maps and institutional affiliations.

Ready to submit your research? Choose BMC and benefit from:

- fast, convenient online submission

- thorough peer review by experienced researchers in your field

- rapid publication on acceptance

- support for research data, including large and complex data types

- gold Open Access which fosters wider collaboration and increased citations

- maximum visibility for your research: over $100 \mathrm{M}$ website views per year

At $\mathrm{BMC}$, research is always in progress.

Learn more biomedcentral.com/submissions 